Int. J. Innovation and Learning, Special issue on: Moving Forward with Synergy from Innovation and Learning : Sustainability Perspective, 201n

\title{
Knowledge Dynamics and Innovation: A Case Study
}

\begin{abstract}
:
This study describes the progress of an innovation from idea to product in a microcompany and analyses the knowledge dynamics in the process. The research seeks to answer the following questions: What is the process through which an innovation develops from idea to product in a micro-company? What kind of knowledge is needed and what kind of phases can be identified in the process? What kind of features of knowledge anchoring can be identified in the innovation process? These are answered through a single case study that uses the knowledge biography technique. The process was tracked and the knowledge dynamics were described. This study will serve as an interesting benchmarking tool for managers and public development agencies. The findings suggest that public actors should pay more attention in their service development to case-specific needs of innovative start-ups. Future studies would benefit from analysing more cases using similar method.
\end{abstract}

Keywords: knowledge dynamics, knowledge biography, knowledge anchoring, innovation, learning, micro-company, growth, Finland

\section{Introduction}

Knowledge is intimately connected to innovation; indeed, changes in knowledge can be seen as the driving force behind innovation, and there are multiple ways in which the general product/innovation lifecycle can be divided into generic phases, stages or states (e.g. Dean, 1950, Golder and Tellis, 2004, Markusen et al., 1986, Schutjens and Stam, 2003). The aim of this study is to describe how an innovation progresses from an idea to a product and analyse the knowledge dynamics of the process, by examining a specific case study in a micro-company in Oulu South region.

The study is based on the work undertaken as part of the Regional trajectories to the knowledge economy - Nordic-European comparisons project (REKENE), which was funded by the Nordic Innovation Centre, and the Developing the innovation environment in Oulu South region (OE INNO) project, which was funded by European Regional Development Funds (ERDF). REKENE is a Nordic spin-off that emerged out of the Regional Trajectories to the Knowledge Economy: A Dynamic Model (EURODITE) project, which was funded by the European Commission and the Directorate for Research under Priority Seven (citizens and governance in a knowledge-based society) of the Sixth Framework Programme [1]. EURODITE and REKENE were both multidisciplinary projects that involved researchers from various disciplines, including economic geography, organisational theory, economics, management theory, business administration and sociology.

The interest in exploring the dynamics of knowledge arises from an understanding that a knowledge-based economy is vital for competitiveness in the global economy. Many regional, national and international policies have been developed to encourage knowledge production and innovation and contribute to economic development. This relatively new focus on the role that knowledge plays in stimulating economic development is significantly related to the strategic goal of the Lisbon summit, "that Europe should become the most competitive and dynamic knowledge-based economy in the world, capable of sustainable economic growth with more and better jobs and greater 
social cohesion' [2]. The progress toward achieving this aim has been slow, and many of the more challenging goals that fall within this wider strategic aim have not been achieved at the hoped-for rate. The European Council adopted a new strategy for employment and economic policy in June 2010, the Europe 2020 Strategy; this vision is smart, sustainable and includes provisions for stimulating and sustaining economic growth (European Commission 2010). The region of Finland known as Oulu South region was chosen as the location of this study, from the seven regions in four Nordic countries that were at the focus of the REKENE project. The Oulu South region is situated in the southern part of Northern Ostrobothnia in Finland; it is not a governmental unit or area; rather, it was formed to increase inter-municipal co-operation and development and to gain the required critical mass to ensure national and international competitiveness. The region consists of three sub-regions and 14 municipalities, with about 90000 inhabitants. Oulu South is one of Finland's main rural areas, but because it offers sufficient employment for its inhabitants, it is known as industrialised countryside'. Furthermore, while the unemployment rate is the lowest in northern Finland, the region is likely to retain a large population of younger people due to its having the highest birth rate in Finland, despite the demographic challenge of widespread emigration from the area. This makes it distinct from other rural areas in Finland, many of which are dealing with significantly ageing populations. Oulu South is also an entrepreneurial region. There are about 4600 active companies in the region, of which the majority $(95 \%)$ are micro-sized [3].

The innovation case study presented here represents a cross-sectoral co-operation between ICT and metal industries. Co-operation between the ICT and metal industries is significant for the economy of the Oulu South area. The adaptation of ICTs to the traditional business sector is seen as a significant response to the challenges of the region. The ability to implement new, wireless IT solutions and automation is regarded as a critical part of the evolution of the mechanical engineering industry. In the region, most machinery manufacturers are small companies with limited opportunities to invest in R\&D. In this case study, we investigate how a PC-free control system for a forest harvester with remote control possibilities was developed, from idea to finished project. We track this from 1996 to 2007 in the company in which the idea was first proposedthe micro-company Areca Electro LP and then track the progress after its transferral to another micro-company-Crelea Ltd.-after 2007. Both organisations were located in Oulu South region.

This study focuses on the knowledge dynamics of a single innovation to garner a better understanding of how knowledge is developed and transferred at a firm level. The aim of studying knowledge dynamics is to unravel the processes of knowledge interactions and to identify the types of actors that are involved in these processes. With this in mind, we defined the following research questions:

1. What is the process through which an innovation progresses from an idea to a product in a micro-sized company?

2. What kind of knowledge is needed and what kind of phases can be identified in the process?

3. What kind of features of knowledge anchoring can be identified in the innovation process?

To address these research questions, a single case study was undertaken. This was deemed the optimum approach for assessing this kind of investigation. According to Yin (1989, p. 23), 'a case study is an empirical inquiry that investigates a contemporary phenomenon within its real-life context, when the boundaries between phenomenon and 
context are not evident and in which multiple sources of evidence are used'. An essential part of the research involved conducting in-depth interviews with key informants. Because the research deals with interactions and networks among actors and is particularly aimed at identifying knowledge exchange and development, this was deemed the best way to discover a significant amount about these processes. The three key individuals who were involved in this particular case of innovation were interviewed and the information they provided was then analysed, using the knowledge biography technique as the predominant methodology.

This study may help and support public actors to ask essential questions in developing their services for micro-companies in order to foster regional development and economic growth. According to Crevoisier and Jeannerat (2008, p. 8), innovative regions are those that are capable of imagining their local activities within a global environment. In order to be innovative, a region must be capable of matching its dynamics to the use and generation of knowledge

This study is made up of five sections. In the introduction, the background, motivation, research problem and research questions are presented. In the second section, the theoretical background of the study is presented, and a brief survey of the relevant knowledge dynamics, types, phases and anchoring is conducted. In the third section, the method undertaken in this study is described. In the fourth section, a description and analysis of the data garnered in this single case study are undertaken; these findings are then examined in light of the research questions. In the final section, a discussion of the main results, limitations and opportunities for further research is presented.

\section{Knowledge Dynamics}

The theoretical background of this study lies in the research framework constructed for the empirical case studies undertaken as part of the EURODITE project and its Nordic spin-off- the REKENE project. These projects examined knowledge dynamics at a regional and sectoral level (also known as territorial knowledge dynamics, TKD) as well as at an individual company level (also known as firm-level knowledge dynamics, FKD). In this study, we focus on knowledge dynamics at the firm level.

Knowledge is widely regarded as a useful economic resource; in this sense, it has been defined as the learning process in human brains, generated and used in personal and collective interactions in various contexts, which uses given individual and firm competences to appropriate new and necessary economically useful knowledge (Dahlström and Hedin, 2010, p. 6). Knowledge is therefore seen as both a resource and a process, both of which are linked to the interactions that occur among actors in the concept of knowledge dynamics. According to Strambach (2008, p. 154), the visible results of knowledge dynamics are innovations in products, services or processes. Knowledge dynamics can be understood as the dynamics that emerge from processes of the creation, use, transforming, movement and diffusion of knowledge. Knowledge is not static; rather it is constantly changing and dependent on context and application.

\subsection{Knowledge types, knowledge phases and knowledge process}

For the purposes of this empirical case study, analytical, synthetic and symbolic knowledge were considered most relevant. Analytical knowledge is defined as researchbased knowledge, developed through scientific exploration. Synthetic knowledge is regarded as the result of combining analytical and (perhaps) symbolic knowledge. Engineering knowledge is a good example of synthetic knowledge, since it derives from application and from scientific research. Symbolic knowledge is largely recognised in 
research on cultural or creative industries. It deals with ideas, symbols and socially constructed commodities. It has been referred to as knowledge about representation (See e.g. Asheim and Coenen, 2006, Strambach, 2008).

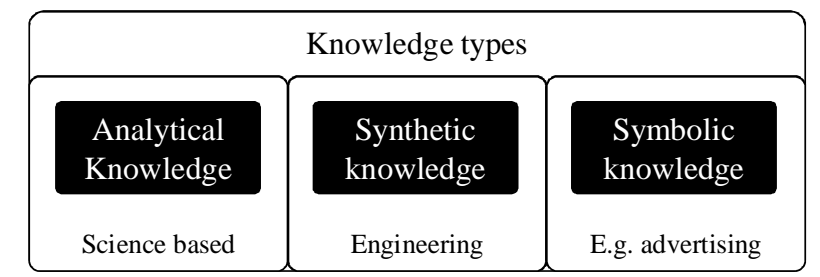

Figure 1. Knowledge types.

A distinction is often made between tacit and codified knowledge when examining knowledge types. Codified knowledge can be transmitted relatively easily to others because it is understood to be knowledge that can be represented either in writing or in digital or analogue format. In contrast, tacit knowledge is understood to be knowledge that is cultivated largely through practice and is embodied in people. It is articulated through practical skills and cannot be reduced to numbers, graphs, maps, diagrams or texts, etc. Face-to-face contact or 'buzz' is, consequently, an important part of tacit knowledge transfer (Collinge et al., 2008, Halkier et al., 2010).

Knowledge phases very seldom progress in a linear way. Usually, development progresses in such a way that various phases take place at the same time; indeed, there may even be loops between these phases. In order to understand the complexity of knowledge dynamics as part of the process of innovation, three knowledge phases are examined in this study - exploration, examination and exploitation.

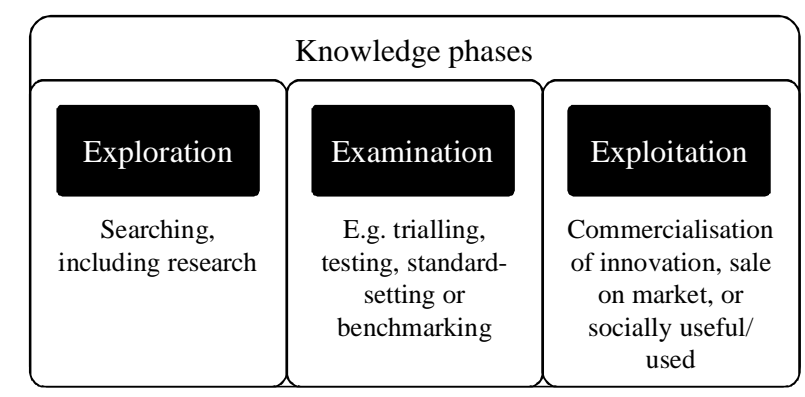

Figure 2. Knowledge phases.

The exploration phase is often described as the first step in the knowledge chain. This phase usually involves searching for new knowledge or maintaining and developing existing knowledge. It is a testing phase, in which the veracity and applicability of the knowledge is considered. Exploitation is regarded as a 'selling' and 'using' phase, in which knowledge is applied to a situation in return for financial, status, position or recognition gains (Halkier et al., 2010, Strambach, 2008).

\subsection{Knowledge anchoring}


The importance of innovation and knowledge transfer in the regional economic development process has increasingly been emphasised. The concept of knowledge anchoring was first developed in the EURODITE project. As a general idea, the concept refers to the ability of an organisation or territory to access external knowledge and make use of it in some way. Anussornnitisarn et al. (2010), Kess et al. (2008) and Phusavat et al. (2009) have highlighted the importance of external knowledge for organisational learning.

James et al. (2010, p. 60) define knowledge anchoring as that knowledge which originates outside of a particular region, but that, in some way, 'sinks in' and is recirculated within that region. It also refers to the processes through which knowledge is used by other firms/institutions within a region (not just the one that found/adopted the knowledge from an external source). This might include developing new knowledge, recombining this external knowledge with existing knowledge and diffusing the knowledge within the region.

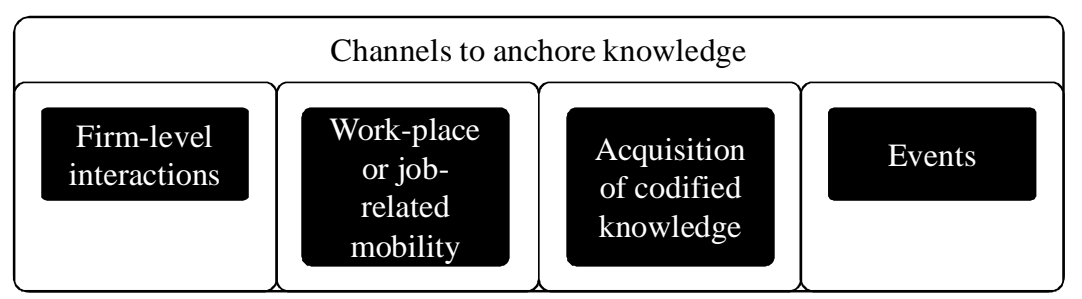

Figure 3. Four main channels to anchor knowledge, as identified in the EURODITE case studies.

The concept of knowledge anchoring is a useful tool with which one can analyse the different mechanisms through which knowledge flows into, and is recirculated within, regions and firms. In this study the knowledge anchoring is mainly viewed in the firmlevel. The EURODITE case studies identified four main 'channels' through which knowledge came to be anchored in: firm-level interactions, work-place or job-related mobility, acquisition of codified knowledge, and events. The inflow and recirculation of knowledge may occur at the same time and in complex mixes of processes and channels. Knowledge anchoring through firm-level interaction refers to, for instance, interaction through organised networks and direct interactions between companies as well as unmediated and mediated interactions. This channel functions only insofar as the individuals that interact do so as representatives of firms, organisations and knowledge institutions. Examples of activities relevant to work place or job-related mobility are people moving to a region, movements of employees within an organisation and business trips. Acquisition of codified knowledge is often connected with academic activities such as events or publications. Gaining access to this can be undertaken through, for example, browsing the Internet and reading publications. Events are arenas for recirculation of knowledge, in which expected and unexpected knowledge interactions can occur because people who would not otherwise meet are brought together, either inside or outside the region (Dahlström and Hedin, 2010, p. 6-7, 82-93).

Knowledge anchoring is useful for analysing the important aspects of knowledge dynamics. Knowledge interactions are characterised by their cross-sectoral, multiscalar and multi-actor nature. 


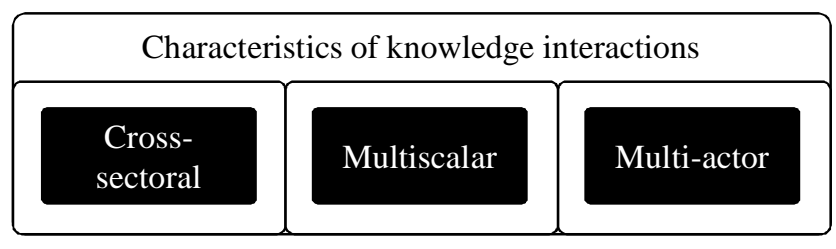

Figure 4. Characteristics of knowledge interactions

Cross-sectoral knowledge interactions are innovative and drive product development. Territorial and firm-level knowledge dynamics include extra-regional interactions. Knowledge interactions include many types of actors, both private and public. All three characteristics of knowledge interactions come together in the analysis of knowledge anchoring. By better understanding knowledge anchoring processes, policies on knowledge interactions, innovations and growth can be selected to adopted that match regional needs as closely as possible (Dahlström and Hedin, 2010, p. 126-127).

\section{The Method}

For the case study presented herein, we adopted a holistic strategy, the process of which is outlined in Figure 5.

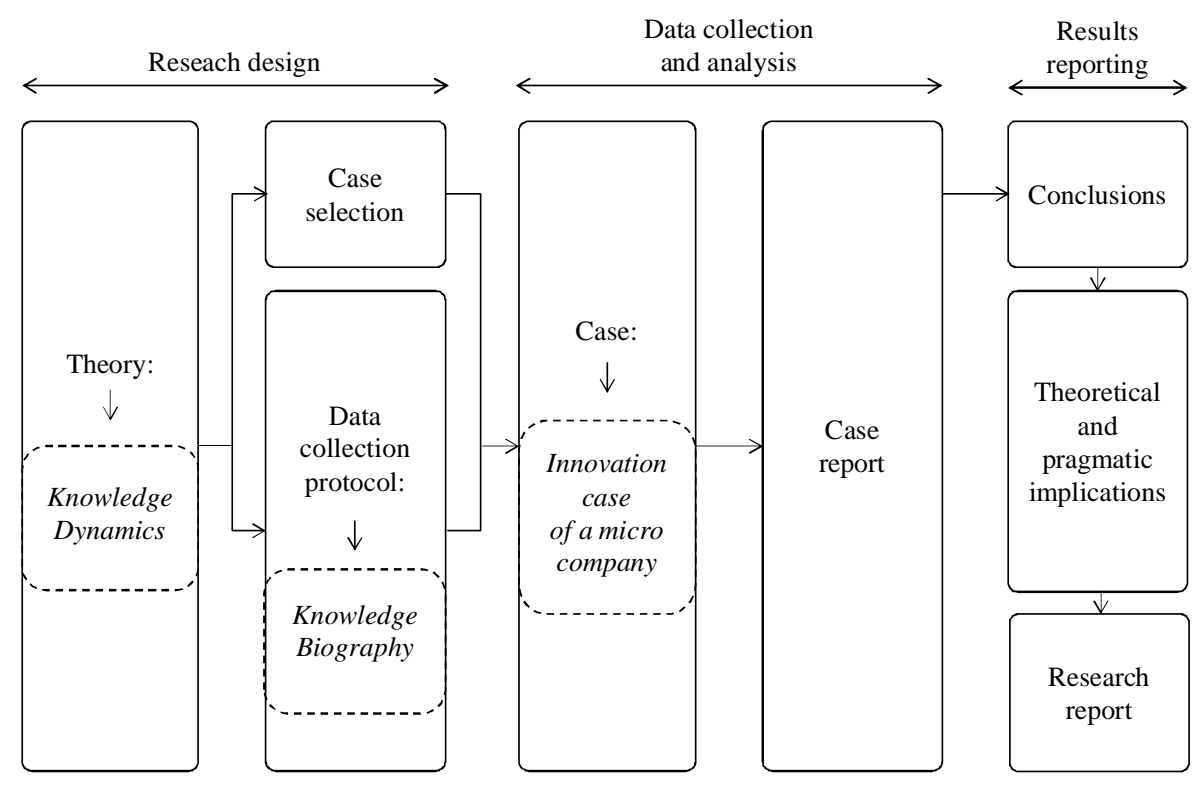

Figure 5. The research process

The study analysed the process of innovation within a micro-company. The definition of a micro-company (and SME) is different in different contexts. The US context, for example, offers many definitions of SME, depending on the industry. For example, in some industries, an SME is defined as any company having fewer than 500 employees. In the European context, an SME is defined as any company having fewer than 250 
employees. The same disparity applies to micro-companies and should be taken into account when studying the SME-related literature. Ayyagari et al. (2007) cover this topic in their globally focused, statistical study on SMEs (p. 416): 'The term SME covers a wide range of definitions and measures, varying from country to country and varying between sources reporting SME statistics. Some of the commonly used criteria are the number of employees, total net assets, sales, and investment level. However, the most common basis for definition is employment, and here again, there is variation in defining the upper and lower size limit of an SME. Despite this variance, a large number of sources define an SME to have a cut-off of 250 employees'. Because of the European context of this case study, we utilise the European definition. Within the SME category, the European Union defines medium-sized firms as having 50-249 employees, small firms as having 10-49 employees and micro-firms as having 0-9 employees (Storey, 2003).

In this study, the empirical data was gathered through semi-structured interviews and public archives related to company in question. Most of the interviews with key informants were conducted face-to-face during fieldwork. The questionnaires were designed to garner information from the informants on questions including the following: How did the innovation process develop from idea to product? What important knowledge interactions occurred during the development of the product? Who were the main actors involved in the development process? Where were they located? What type of knowledge did they contribute to the process? What was the core knowledge involved in the genesis and development of this innovation? How did the core knowledge of the innovation arise and how was it developed? During the interview, the interviewer summarised the explanations provided by the interviewees in order to avoid a biased or incomplete interpretation. The case study evidence was then saved in the database. The case study evidence was collected by a researcher trained for data collection procedures and familiar with the theoretical background to this study. The data collection process took place in 2008 and 2009; following this, an inclusive and iterative process was used to analyse the data, and the main findings were summarised.

The knowledge biography technique - an innovative approach that provides a deeper understanding of knowledge dynamics in firms and regions-was used as the main technique for interpreting the data. The development of the innovative process was tracked and interviews were used to obtain basic information about the space and time dimensions of the knowledge dynamics that took place as part of this process. The knowledge biography approach allowed us to capture the diversity of the social environment of the firm to identify the precise ways in which the knowledge flowed and the information from various partners inside and outside the firm was transmitted and exchanged (Dahlström and Hedin, 2010, p. 11).

\section{Creating a Knowledge Biography of an Innovation}

The innovation analysed here is the development of a PC-free control system for a forest harvester with remote control possibilities; we tracked this innovative product from idea to product. The innovation was first proposed in 1996, within the micro-firm Arsca Electro LP; it remained within this company until 2007, when it was transferred to the micro-firm Crelea Ltd. Both organisations are located in Finland's Oulu South region.

Based on the data obtained from the interviews, three innovation phases were identified: 1) ideation, 2) product development and 3) commercialisation of the product. The innovation phases were found to overlap somewhat, and this should be taken into account when reading the description of the innovation development process. Figure 6 illustrates the innovation phases and the key knowledge interactions that occured among the actors involved. 


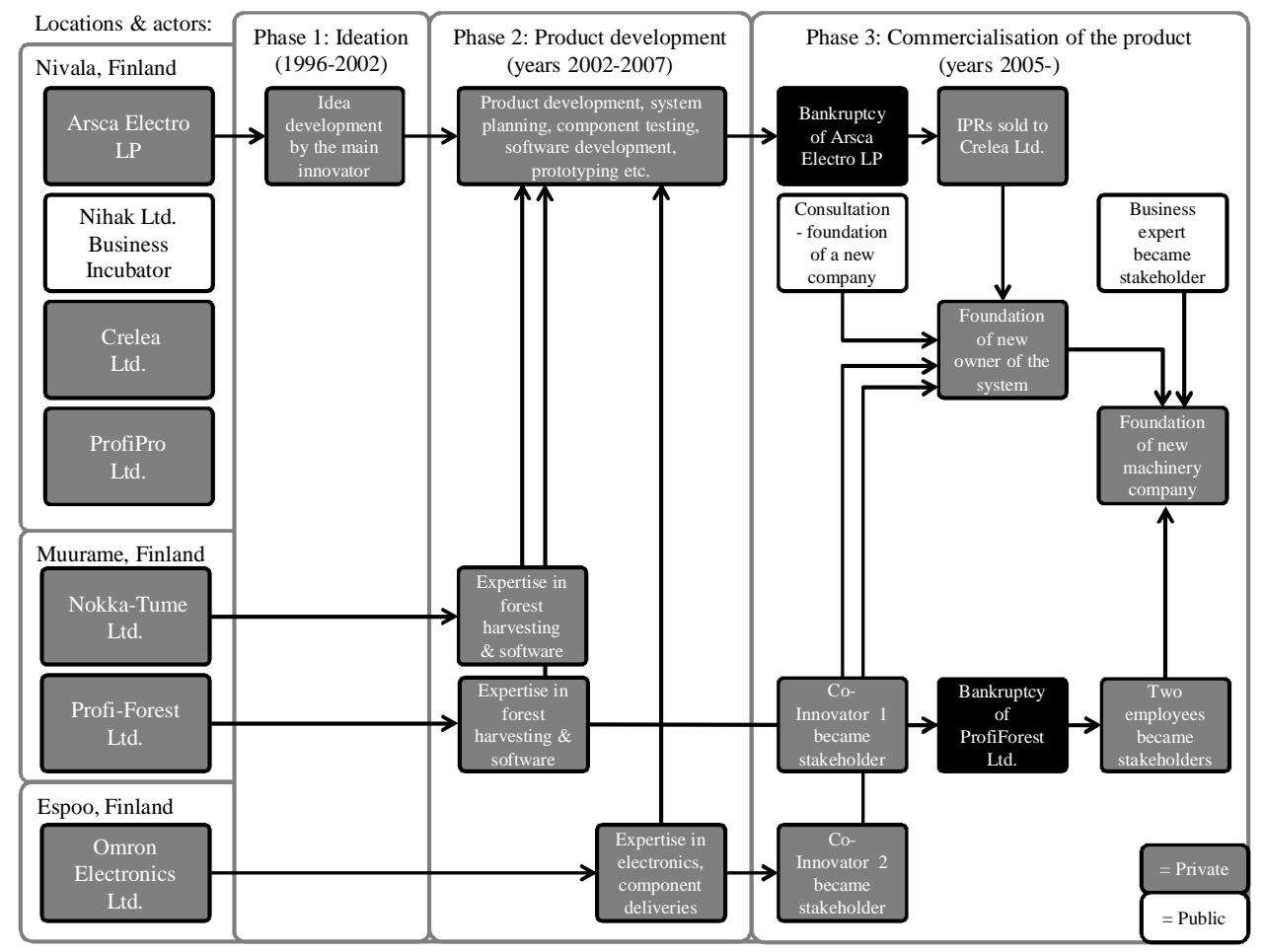

Figure 6. Knowledge biography of an innovation

\subsection{Phase 1: Ideation (1996-2002)}

The knowledge dynamics of the first phase of the innovation process are based on the actions of the main innovator, an entrepreneur who, in 1996, worked for Arsca Electro LP; he first had the idea for the control system while he was installing electrics in forest harvesters. He believed the electronics system that was in place at the time was too complex, too vulnerable to faults and too laborious to make, and he had the idea to replace the numerous hand-adjusted functions with one centralized adjustment and control system.

The main innovator already had significant knowledge related to the innovation, and this was important in developing the idea further. He had garnered significant working experience related to planning and engineering different kinds of electricity, electronics, control systems and forest machines, because Arsca Electro LP had been undertaking electronics installations on forest machines since 1986. He had also been an entrepreneur between 1978 and 2007 and had been educated as an auto mechanic and an electronics installation technician. While working, he had also studied (self-study) academic publications and manuals related to electrical engineering, electronics and data communication, including material secured from his brother from the data communications engineer education programme at Oulu Technical Institute and material on fuzzy logic that he had bought from a teacher at the Jyväskylä Technical Institute. 
The innovation process began in 1996, when the main innovator first told the forest harvester manufacturer Nokka-Tume Ltd. about his idea and asked them to start a product development process for a forest harvester control system, in conjunction with Arsca Electro LP. However, at that point, Nokka-Tume refused, as they regarded the idea as too challenging and risky. Arsca Electro LP was unable to initiate product development without the help of another company, due to its financial situation. However, between 1996 and 2002, the main innovator developed his idea further in his free time using his own money. Finally, after 6 years, in 2002 Nokka-Tume decided to start the development process in conjunction with Arsca Electro LP.

The success of the innovation process relied on the fact that Arsca Electro LP and the forest harvester manufacturer had had a long cooperative relationship. The main innovator was only willing to initiate product development with a partner with whom he already had a confidential relationship. The relationship was built when the main innovator worked with different versions of the same forest harvester successively for three different firms Nokka-Koneet Ltd., Nokka-Tume Ltd. and Profi-Forest Ltd. These firms owned intellectual property rights of the harvester.

\subsection{Phase 2: Product development (2002-2007)}

The knowledge dynamics of the second phase of the innovation process were mainly based on cooperation between three individuals-the main innovator and two coinnovators. Actual product development started in 2002 and was a cooperative initiative between Arsca Electro LP and Nokka-Tume, who also brought a long-term employee (co-innovator 1) on board to join the development process. Co-innovator 1 was an important actor in the second phase because he was an expert in programming and software and had been educated as an information technology engineer. A second coinnovator, an employee of Omron Ltd., which, for many years, had been an important partner to Arsca Electro LP, also joined the process at this stage. Co-innovator 2 was also an important actor in this phase because of his expertise in electronics and his education as an electricity and automation technician. The main innovator had known both coinnovators before and had asked for their involvement based on successful earlier cooperation with them.

In 2003, Nokka-Tume Ltd. sold its forest harvester manufacturing to a new company, Profi-Forest Ltd. In terms of the innovation process, it was important that the development process be allowed to continue without any disruption, despite the change in the harvester manufacturing ownership. The process was allowed to continue without disruption because Arsca Electro LP became responsible for all of the electricity installations on Profi-Forest's harvesters; in addition, co-innovator 1 moved from NokkaTume to Profi-Forest, while co-innovator 2 remained in the development process, because there was no need to change electronics supplier.

From the forest harvester manufacturer's point of view, it was important to get feedback from harvester users about the new control system as soon as possible. The main innovator and the two co-innovators were able to finish the prototype of the first forest harvester with the new control system in 2005; they presented it at a forestry trade fair in the same year, where it was received favourably. Further development of the control system continued until 2007, when Arsca Electro LP sold the intellectual property rights of the control system to Crelea Ltd., a company that was specifically founded to take responsibility for the new system and its future development. 


\subsection{Phase 3: Commercialisation of the product (2005-date)}

The knowledge dynamics of third innovation phase were and are much more complex than they were in phases 1 and 2. There are more actors involved, and some significant organisational changes took place that affected the development of the new system. This was also the only phase in which a public organisation influenced the innovation process.

Because the new forest harvester system had received positive feedback from users during the trade fair in 2005, the prototype was developed to a finished product quickly, and the manufacturer was able to start marketing the harvester with the new control system. In terms of this step, the harvester manufacturer's knowledge about trade fairs, marketing and the forestry sector was an important factor in marketing the control system as an essential part of the harvester.

As a result of Arsca Electro LP's economic problems, tax debits accumulated and the tax authorities bankrupted the company in 2007. Arsca Electro LP sold the intellectual property rights of the control system to the newly founded company, Crelea Ltd., and two sons of the main innovator became the main stakeholders in Crelea Ltd., along with the co-innovators, who were asked to join by the main innovator, who wanted to ensure their long-term commitment to the system. The main innovator did not want to become a stakeholder because of the economic problems of Arsca Electro LP; however, he acted as an important expert and advisor to Crelea Ltd. Also the other stakeholders were invited to be stakeholders in the new company by the main innovator because their knowledge was regarded as a necessary resource in the further development of the control system. One works as an industrial designer in an international machine manufacturer and the other is responsible for the international marketing affairs of another machine manufacturer.

The Business Incubator of the municipal-run development company Nihak Ltd has supported Crelea Ltd. since 2007, when the new company was still in its start-up phase and was requesting public money to finance its development actions. Nihak Ltd's Business Incubator was the only public organisation that exerted influence on this innovation. The main innovator did not have significant local business partners that would benefit his innovative system. He did not actively seek private or public partners from the Oulu South region because he did not believe that this would have benefitted his innovation.

The economic depression of 2008 caused problems in the forest sector, in particular for small machine manufacturers, such as Profi-Forest. As a result of economic problems, the harvester manufacturer Profi-Forest went bankrupt in 2009, and a new company, Profi-Pro Ltd., was established to continue manufacturing harvesters. Profi-Pro bought the whole harvester manufacturing sector from Profi-Forest and transferred the production from Muurame to Nivala, where Crelea Ltd. was based.

The Business Incubator business expert played an important role in phase 3 of the innovation process, by adding their business experience and expertise to the process. The bankruptcy of the harvester manufacturer meant that the future of the innovative harvester system was very uncertain. With this in mind, it was strategically significant that the business expert already knew Crelea Ltd. quite well when he started to search possibilities to start a new manufacturing firm. He was one of the founders of, and became a stakeholder in, the new manufacturing company Profi-Pro. In ensuring the successful continuation of the innovation process, it was also significant that Crelea Ltd. became a stakeholder of Profi-Pro, and that two former employees of Profi-Forest, both specialised in marketing, became stakeholders as well. 


\section{Discussion}

This study describes how an innovation process develops from idea to final product and analyses the knowledge dynamics within this process.

The detailed knowledge biography of the innovation, as presented in section 4, answered research question 1 . We gave a detailed description of how a single innovation can progress from idea to product in three, somewhat overlapping, phases.

The answer to research question 2 can be seen, in a condensed version, in Figure 7. In Figure 7, the innovation process takes place within a framework of knowledge types and knowledge phases (See Figures 1 and 2), according to the theoretical analysis conducted in this study.

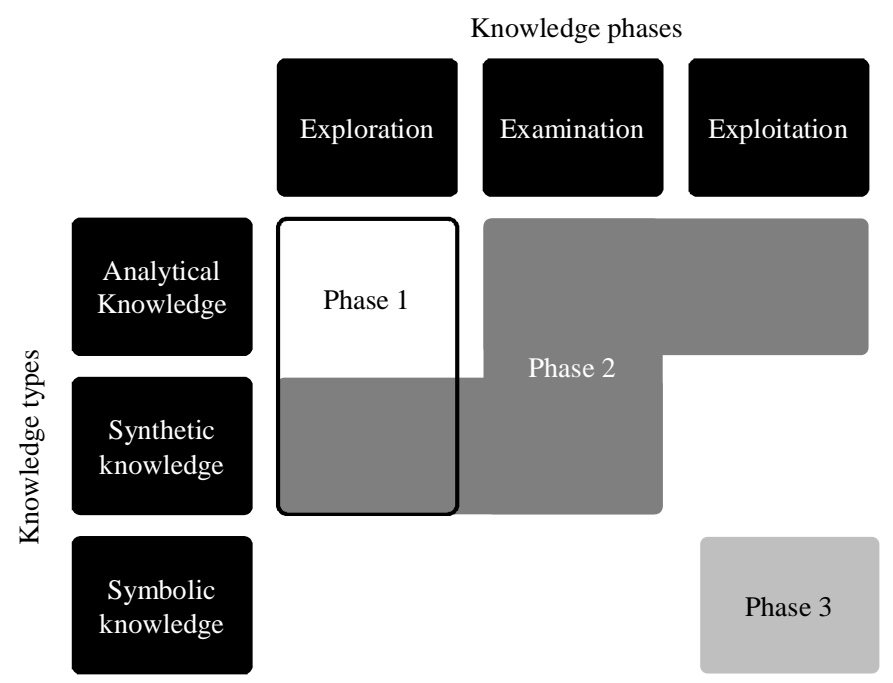

Figure 7. The phases of the innovation process, projected through knowledge types and knowledge phases

The first phase of the innovation process (ideation) is clearly an explorative knowledge phase, in which both analytical and synthetic knowledge was essential. The main innovator gained the requisite knowledge for the innovation by undertaking selfstudy and testing different components and couplings independently.

The second phase (product development) was more complex. During this phase, the innovation process was intensive, and all the knowledge phases (exploration, examination and exploitation) were identified. All of the key persons were involved, which accelerated the development process. The process narrowed its focus, concentrating almost entirely on planning and producing the prototype and testing the requisite components. After the presentation of the prototype, the innovation process continued; further development of the product was conducted. The knowledge needed in this phase was analytical and synthetic.

The third phase, (the commercialisation of the product) represents the exploitative knowledge phase. In this phase, symbolic knowledge was decisive, especially when the prototype was introduced at the trade fair. Symbolic knowledge in this phase played an essential role in planning for and attending the fair and in undertaking other marketing 
actions, which were undertaken almost entirely on the basis of the actors' previous experience of trade fairs, marketing and the market knowledge of the forestry sector.

For comparison, when analysing the innovation phases in terms of tacit and codified knowledge, it is clear that codified knowledge was especially important in phases 1 and 2. In this case, codified knowledge consists of common manuals on electricity, electronics, programming and software, that the key persons studied and used. Also wellknown recognised standards are also part of the canon of codified knowledge. Tacit knowledge was seen to be important in all phases. Personal contacts played a crucial role in ensuring the progression of the innovation process. The most important knowledge behind the innovation was that of personal expertise. Despite the fact that the key actors all worked in different parts of Finland, they were able to share their tacit knowledge, because of their reliance on each other.

In terms of research question 3, knowledge anchoring was found to play a very interesting role in the innovation process. The core knowledge was anchored mainly in the key individuals involved in the process and their personal relationships. The main innovator had no significant local business partners from which his innovation could benefit. He did not actively seek private or public partners from the Oulu South region and public organisations from the region played only a minor in the case. Despite this, this survey can serve as a useful benchmarking tool for managers and public development agencies. The findings suggest that public actors should pay more attention in their service development to catering for the case-specific needs of innovative start-ups and that public actors should better understand how to support micro-companies. The results of this study show how micro-companies can function effectively with fewer financial and human resources than those in large enterprises. The characteristics of knowledge interactions and the channels through which knowledge is anchored, as revealed by the findings can be seen (in a condensed version) in Table 1.

Table 1. Characteristics of knowledge interactions and channels through which knowledge is anchored

\begin{tabular}{|c|c|c|c|c|}
\hline & Types & $\begin{array}{l}\text { Phase } 1 \\
\text { Ideation }\end{array}$ & $\begin{array}{c}\text { Phase } 2 \\
\text { Product development }\end{array}$ & $\begin{array}{c}\text { Phase } 3 \\
\text { Commercialisation }\end{array}$ \\
\hline \multirow{5}{*}{ 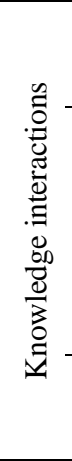 } & Multiactor & $\begin{array}{l}\text { Main } \\
\text { innovator }\end{array}$ & $\begin{array}{l}\text { Main innovator and } \\
\text { two co-innovators }\end{array}$ & $\begin{array}{l}\text { Main innovator, co- } \\
\text { innovator and forest } \\
\text { machine manufacturer }\end{array}$ \\
\hline & \multirow{3}{*}{ Multiscalar } & Home town & $\begin{array}{c}\text { Home town and two } \\
\text { others } 250 \text { and } 500 \mathrm{~km} \\
\text { away }\end{array}$ & $\begin{array}{c}\text { Home town and one } \\
\text { other town } 250 \mathrm{~km} \\
\text { away }\end{array}$ \\
\hline & & & $\begin{array}{l}\text { International fair in } \\
\text { Sweden }\end{array}$ & $\begin{array}{l}\text { International fair in } \\
\text { Sweden }\end{array}$ \\
\hline & & $\begin{array}{l}\text { Slow intensity } \\
\text { process }\end{array}$ & Fast intensity process & $\begin{array}{l}\text { Medium intensity } \\
\text { process }\end{array}$ \\
\hline & $\begin{array}{l}\text { Cross- } \\
\text { sectoral }\end{array}$ & Electronics & $\begin{array}{l}\text { Electronics, ICT and } \\
\text { machinery }\end{array}$ & $\begin{array}{l}\text { Electronics, ICT, } \\
\text { machinery and } \\
\text { marketing }\end{array}$ \\
\hline \multirow{3}{*}{ 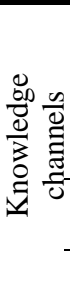 } & Firm-level & $\begin{array}{l}\text { Main } \\
\text { innovator's } \\
\text { firm }\end{array}$ & $\begin{array}{l}\text { Main innovator's firm } \\
\text { Direct interactions with } \\
2 \text { other companies }\end{array}$ & $\begin{array}{l}\text { Direct interactions } \\
\text { among } 4 \text { companies } \\
\text { Interactions with } \\
\text { public business } \\
\text { services }\end{array}$ \\
\hline & Mobility & & Business trips & $\begin{array}{c}\text { Business trips } \\
\text { Employee transfers }\end{array}$ \\
\hline & Codified & Self-study: & Self-study: & Collecting knowledge \\
\hline
\end{tabular}




\section{Knowledge Dynamics and Innovation: A Case Study}

\begin{tabular}{cccc}
\hline knowledge & $\begin{array}{c}\text { manuals, academic } \\
\text { publications }\end{array}$ & $\begin{array}{c}\text { manuals, academic } \\
\text { publications }\end{array}$ & for marketing plan \\
\hline Events & & $\begin{array}{c}\text { Prototype in the trade } \\
\text { fair }\end{array}$ & $\begin{array}{c}\text { Marketing in the trade } \\
\text { fair }\end{array}$ \\
\hline
\end{tabular}

As our innovation case study makes clear, symbolic knowledge (phase 3 ) is related to increased knowledge interactions, and this makes the innovation process more complex. As the innovation process develops, the number of actors increases, and the geographical dimension widens from a local to an international level.

The intensity of the innovation process varies as it progresses and the cross-sectoral dimension diversifies. Even though the main innovator was very independent, especially in the early stages of the process, a great variety of knowledge anchoring channels were identified as playing an important role in the innovative process.

A construct validity of this case study is based on a research plan that was used as a road map throughout the study. The case study used multiple sources of evidence, including interviews and public archive documents and the chain of evidence was carefully established. Moreover, the key informants reviewed the draft case study reports during the process. The internal validity of the study relies on the research design. The causal relationships were built carefully to avoid any biases. As external validity is concerned, the findings of a single case study cannot be generalised to theory (Yin, 1989). However, through later analysis of replications in other innovation cases, it becomes possible. For evaluation of the reliability of the study, the following points are highlighted. Case study protocol was used during the data collection phase, the case database was established and the data collection process was documented - the research was conducted so that an auditor could repeat the procedures and arrive at the similar kinds of results. Anyhow, the researchers own paradigm may have an affect the findings in this type of case study - this affect was minimised by an inclusive and iterative data collection process, which enabled verification of the interpretations during the process. Moreover, several actors were interviewed and several people's views were obtained in the interpretation.

This kind of entrepreneurship provides a challenge to the regional innovation system. In future studies, it would be interesting to use the method of knowledge biography to examine other innovation process case studies. We hope to refine and develop this method and then apply it to future studies. We also suggest that future research examine the results of similar analyses made in micro-companies in other European countries or elsewhere. The role of intermediaries in the support of micro-companies in this challenging area requires closer examination. We hope, in the future, to investigate how public business services and the development of activities in technology parks will be able to provide support to micro-companies and SMEs in rural and sparsely populated areas. We hope in assess the ways in which these services will confront the challenges inherent in entrepreneurial models such as that examined in our case study. Future studies could focus on public business services and assess whether, and if so how, these services meet the needs of the companies.

\section{References}

Anussornnitisarn P, Sanpanich S, Phusavat K \& Kess P (2010) Sustaining organisational innovation and learning through external knowledge. International Journal of Innovation and Learning 7(1): 85-99. 
Asheim, B.T., and Coenen, L. (2006), 'Contextualising regional innovation systems in a globalising learning economy: on knowledge bases and institutional frameworks', The Journal of Technology Transfer, Vol. 31 No. 1, pp. 163-173.

Ayyagari, M., Beck, T., and Demirguc-Kunt, A. (2007), 'Small and medium enterprises across the globe', Small Business Economics, Vol. 29 No. 4, pp. 415-434.

Collinge, C., Macneill, S., James, L., Larsson, A., Widmaier, B., Jeannerat, H., Butzin, A., and Vale, M. (2008), 'Reporting Template WP6 FKD Final Reports', unpublished project internal working paper, EURODITE.

Crevoisier, O., and Jeannerat, H. (2008), 'The Territorial Knowledge Dynamics: from the proximity paradigm to multi-location milieus', working paper, University of Neuchatel, 18 February.

Dahlström, M., and Hedin, S. (eds.) (2010), Regional trajectories to the knowledge economy - Nordic-European comparisons, Nordic Innovation Centre.

Dean, J. (1950), 'Pricing Policies for New Products', Harvard Business Review, Vol. 28 No. 6, pp. 45-53.

European Commission (2010), Europe 2020: A Strategy for Smart, Sustainable and Inclusive Growth: Communication from the Commission, Publications Office, EU.

Golder, P.N., and Tellis, G.J. (2004), 'Growing, Growing, Gone: Cascades, Diffusion, and Turning Points in the Product Life Cycle', Marketing Science, Vol. 23 No. 2, pp. 207-218.

Halkier, H., Dahlström, M., James, L., Manniche, J., and Smed Olsen, L. (eds.) (2010), Knowledge Dynamics, Regional Development and Public Policy, Department of History, International and Social Studies, Aalborg University.

James, L., Dahlström, M., and Smed Olsen, L. (2010), 'Knowledge Anchoring in European Regions: Policy Implications', in Halkier, H., Dahlström, M., James, L., Manniche, J., and Smed Olsen, L. (eds.), Knowledge Dynamics, Regional Development and Public Policy, EURODITE, EU.

Kess P, Phusavat K \& Takala J (2008) Managing external knowledge: framework for organisational life cycles. International Journal of Innovation and Learning 5(3): 255-265.

Markusen, A.R., Hall, P., and Glasmeier, A. (1986), High tech America: the what, how, where, and why of the sunrise industries, Allen \& Unwin, Boston.

Phusavat K, Sanpanich S, Kess P \& Muhos M (2009) The roles of external knowledge in organisational learning and development. International Journal of Innovation and Learning 6(5): 537-549.

Schutjens, V., and Stam, E. (2003), 'The Evolution and Nature of Young Firm Networks: a longitudinal Perspective', Small Business Economics, Vol. 21 No. 2, pp. 115-134.

Storey, D.J. (2003), 'Entrepreneurship, Small and Medium Sized Enterprises and Public Policy', in Acs, Z.J., and Audretsch, D.B. (eds.), Handbook of Entrepreneurship Research, Dordrecht, pp. 473-511.

Strambach, S. (2008), 'Knowledge-Intensive Business Services (KIBS) as drivers of multilevel knowledge dynamics', International Journal of Services Technology and Management, Vol. 10 No. 2, pp. 152-174.

Yin, R.K. (1989), Case study research: Design and methods, Sage Publications, Beverly Hills.

\section{Endnotes}

[1] Read more about the REKENE project at: http://www.nordregio.se/en/NordregioResearch/REKENE/ and about the EURODITE project at: http://ec.europa.eu/research/social-sciences/projects/321_en.html. 
15 Knowledge Dynamics and Innovation: A Case Study

[2] The Lisbon European Council 2000.

[3] Statistics Finland 2011. 